\title{
(Des)conexiones (trans)atlánticas: recepciones estadounidenses del feminismo italiano de la diferencia sexual
}

\author{
(Trans)atlantic (dis)connections: \\ US receptions of Italian feminsm of sexual difference
}

\author{
ARÁNZAZU HERNÁNDEZ PIÑERO*
}

\begin{abstract}
Resumen: En dos momentos diferentes, 1989 y 2005, dos autoras cuyo ámbito es el feminismo estadounidense, Teresa de Lauretis y Linda Zeri1li, dirigen su atención hacia el feminismo italiano de la diferencia sexual, particularmente, a la obra No creas tener derechos de la Librería de Mujeres de Milán, y lo hacen intervenir en las discusiones que cada una de ellas sostienen en su contexto. ¿Qué discusiones son éstas y qué potencialidades encuentran Lauretis y Zerilli en el pensamiento y la práctica de la Librería de Mujeres de Milán? En el presente artículo, trataré de responder a estas preguntas. Para ello, argumentaré que las interpretaciones que cada una de las autoras elaboran implican un cuestionamiento así como un desplazamiento de los términos en torno a los cuales se había configurado el debate feminista estadounidense entre la década de los ochenta y los noventa, a saber, en términos de la polémica esencialismo/antiesencialismo y de la controversia diferencia sexual/diferencias (sexualidad, raza, clase, principalmente). A lo largo de esta argumentación intentaré mostrar el carácter original de ambas recepciones, tanto por la riqueza
\end{abstract}

\begin{abstract}
In two different moments, 1989 y 2005 , two authors working in the field of US feminism, Teresa de Lauretis y Linda Zerilli, direct their attention to Italian feminism of sexual difference, more concretely to the work Non credere di avere dei diritti (translated as Sexual difference) of the Milan Women's Bookstore Collective, and they make intervene in the discussions that each one of them holds in their respective contexts. Which are these discussions and what potentialities do Lauretis and Zerilli find in the thought and practice of the Milan Women's Bookstore Collective. In this paper I will try to answer these questions. I shall argue that the interpretations of each one of these two authors imply a questioning as well as a shift of the terms around which US feminist debate was organized between the decades of the 80's and 90 's, namely around the polemic essentialism/ anti-essentialism and the controversy sexual difference/differences (mainly of sexuality, race, class). Along this argument I will try to show the original character of both receptions in terms of the philosophical-political richness of Lauretis'
\end{abstract}

Fecha de recepción: 30/05/2014. Fecha de aceptación: 09/07/2014.

* Universidad de Zaragoza, Profesora Contratada Doctora, aranzazu@unizar.es. Líneas de investigación: teoría feminista contemporánea y filosofía contemporánea. Publicaciones: Amar la fluidez. Teoría feminista y subjetividad lesbiana, Zaragoza, Eclipsados, 2009 y «Escrituras del deseo entre mujeres: Hélène Cixous y Monique Wittig», en: B. Suárez Briones: Las lesbianas (no) somos mujeres. En torno a Monique Wittig, Barcelona, Icaria, 2013, pp. 149-183.

Este trabajo se inserta en el proyecto «Justicia, ciudadanía y género: feminización de las migraciones y derechos humanos» (FFI2011-24120). 
filosófico-política de las lecturas efectuadas por Lauretis y Zerilli como por el hecho de que constituyen valiosas excepciones al desconocimiento generalizado del feminismo italiano de la diferencia sexual por parte de las feministas estadounidenses.

Palabras clave: diferencia sexual, Librería de Mujeres de Milán, libertad femenina, libertad política y diferencias entre mujeres. and Zerilli's interpretations as well as in relation to the fact that both constitute valuable exceptions to the generalized ignorance of Italian feminism of sexual difference by US feminists.

Key words: sexual differences, Milan Women's Bookstore Collective, feminine fredoom, political freedom and women's differences.

En dos momentos diferentes, 1989 y 2005, dos autoras cuyo ámbito es el feminismo estadounidense, Teresa de Lauretis y Linda Zerilli, dirigen su atención hacia el feminismo italiano de la diferencia sexual, particularmente, a la obra No creas tener derechos de la Librería de Mujeres de Milán, y lo hacen intervenir en las discusiones que cada una de ellas sostienen en su contexto. ¿Qué discusiones son éstas y qué potencialidades encuentran Lauretis y Zerilli en el pensamiento y la práctica de la Librería de Mujeres de Milán? ¿Por qué habrían de resultarnos significativas estas dos recepciones?

Dos factores han llamado poderosamente mi atención: en primer lugar, el hecho de que, a excepción de los trabajos de Lauretis y Zerilli ${ }^{1}$, el feminismo italiano de la diferencia sexual haya permanecido prácticamente ausente de los debates feministas estadounidenses, lo que contrasta marcadamente con las controversias suscitadas con respecto al feminismo francés de la diferencia sexual durante la década de los ochenta. Esta ausencia tampoco ha pasado desapercibida para nuestras autoras: «El feminismo italiano (...) es virtualmente desconocido aquí. Con muy pocas excepciones, -sostiene Lauretis- sus textos críticos no han sido traducidos, ni discutidos o citados por las feministas norteamericanas o británicas $»^{2}$. Zerilli, dieciséis años después, además de suscribir la afirmación de Lauretis, observa que la traducción de No creas tener derechos al inglés, como Sexual Difference ${ }^{3}$, a cargo de Patricia Cigogna y la propia Teresa de Lauretis, no modificó este desconocimiento. Así, la autora trata de analizar, como parte de su interpretación, las razones por las cuales «una obra desafiante», como la de la Librería de Mujeres de Milán, «jamás encontró lectoras entre las feministas estadounidenses» ${ }^{4}$. ¿Por qué, cabría preguntarse, esta obra es, en opinión de Zerilli, «la gran ausente en los así llamados debates de la categoría mujeres en los años noventa» ${ }^{5}$ ? Este interrogante apunta al segundo aspecto que me ha resultado significativo.

$1 C f$. Lauretis, T. de, «The Essence of the Triangle, Or: Taking the Risk of Essentialism seriously», differences, $\mathrm{n}^{\circ}$ 1/2, 1989, pp. 3-37 (hay traducción: Laurestis, T. de, «La esencia del triángulo, o tomarse en serio el riesgo del esencialismo: teoría feminista en Italia, los E.U.A. y Gran Bretaña», debate feminista (México D.F.), $\mathrm{n}^{\circ} 2$, septiembre 1990, pp. 77-115); Lauretis, T. de, «The Practice of Sexual Difference and Feminist Thought in Italy: An Introductory Essay», en: Milan Women's Bookstore Collective: Sexual Difference, Bloomington, Indiana University Press, 1990, pp. 1-21; y Zerilli, L., «Capítulo III. Las feministas hacen promesas: Sexual Difference del Colectivo de Milán y el proyecto de construcción-de-mundo», en: L. Zerilli: El feminismo y el abismo de la libertad, Buenos Aires, FCE, 2008, pp. 187-238.

2 Lauretis, T. de, «La esencia», op. cit., p. 90.

3 Milan Women's Bookstore Collective, Sexual Differences, Bloomington, Indiana University Press, 1990.

4 Zerilli, L., op. cit., p. 187.

5 Ibíd. 
En segundo lugar, el papel que juegan las interpretaciones de la Librería de Mujeres de Milán que cada una de las teóricas citadas elabora: en ambos casos, éstas permiten a las autoras reconfigurar el marco de discusión en el que participan, pues los términos de los debates en el feminismo estadounidense son presentados, sobre todo por Linda Zerilli, como generadores de «una sensación de agotamiento o crisis» ${ }^{6}$. Ahora bien, ¿a qué debates nos referimos?, ¿se trata de los mismos para ambas autoras? Grosso modo, podríamos responder afirmativamente a esta última pregunta si consideramos que los debates de los que se trata son los motivados por la irrupción del postestructuralismo en el contexto del feminismo y una de sus claves de discusión la articulada en torno al tópico esencialismo/antiesencialismo. Por ejemplo, el artículo de Lauretis dibuja una posición crítica en torno al modo en que éste se ha planteado. No obstante, es preciso considerar la distancia temporal que separa ambas obras y lo que ésta entraña: mientras que Lauretis interviene en los inicios del debate, Zerilli participa transcurridos más de quince años en lo que, desde principios de los noventa, se había denominado el «debate en torno a la categoría mujeres». Así, Zerilli, más que atender a la polémica acerca del esencialismo, se preocupa por analizar las formas en que el feminismo estadounidense e italiano han abordado las diferencias entre mujeres con el propósito de evaluar las consecuencias filosófico-políticas de lo que llama el «colapso de la categoría unificada «mujeres»» ${ }^{7}$ y estimar la posibilidades del feminismo contemporáneo tras dicho colapso.

\section{Contextos: el feminismo italiano de la diferencia sexual en las (des)conexiones (trans)atlánticas}

A propósito del debate suscitado a raíz de la recepción estadounidense del feminismo francés de la diferencia sexual, autoras como Domna Stanton o Rosi Braidotti han hablado de una «desconexión transatlántica» ${ }^{8}$ en el feminismo. Esta última autora ha reconstruido las claves de esta discusión en términos de las divergencias conceptuales y políticas que distinguen a lo que considera las dos grandes corrientes de la teoría feminista contemporánea, a saber, la teoría anglosajona de género y el pensamiento europeo de la diferencia sexual.

La recepción del feminismo francés de la diferencia sexual se produce en un contexto en el que, a grandes rasgos, el feminismo estadounidense se hallaba inmerso en un debate fuertemente polarizado entre partidarias de la igualdad y de la diferencia; representada la primera opción por el feminismo liberal y la segunda por el cultural ${ }^{9}$. Aunque, como afirma Elvira Burgos, el «conflicto de paradigmas» «no puede, en absoluto, reducirse al antagonismo entre igualdad y diferencia» ${ }^{10}$, autoras como Linda Alcoff y Joan Scott, entre otras,

6 Ibíd., p. 75.

7 Ibid., p. 14.

8 Braidotti, R., «Sexual Difference Theory», en: A. Jaggar e I. Young (eds.): A Companion to Feminist Philosophy, Londres, Blackwell, 2000, p. 298. También cf. Metamorfosis. Hacia una teoría materialista del devenir, Madrid, Akal, 2005, pp. 46-53. Stanton, D., «Language and Revolution: the Franco-American Disconnection», en: H. Eisenstein y A. Jardine (eds.): The Future of Difference, Boston, G.K. Hall \& Co., 1980.

$9 C f$. Alcoff, L., «Feminismo cultural vs. Post-estructuralismo: la crisis de la identidad de la teoría feminista», Debats (Valencia), $\mathrm{n}^{\circ}$ 76, primavera 2002, en http//:www.alfonselmagnanim.com/debats/76/espais02.

10 Burgos Díaz, E., «Conflicto de paradigmas: «género» $\mathrm{y}$ «diferencia sexual»», Thémata (Sevilla), nº 35, $2005, \mathrm{p}$. 713. 
aprecian que la recepción estadounidense del feminismo francés de la diferencia sexual intervino de forma decisiva en este debate al introducir nuevos elementos y contribuyó a revisarlo y desplazarlo ${ }^{11}$. Una de las vías para replantear este debate la emprendió un sector del feminismo estadounidense al vincularse con el postestructuralismo y proponer pluralizar la diferencia, hablando entonces de diferencias, con el objeto de criticar la lógica binaria y su corolario de oposiciones jerárquicas entre las que la de identidad/diferencia se inscribiría.

Otra de las sendas abiertas la iniciaron los feminismos lesbiano, negro, chicano y de las mujeres de color, a saber, la de las diferencias entre las mujeres. Tales corrientes cuestionaron el debate igualdad-diferencia porque presuponía una identidad femenina homogénea, que éstas desvelaron como heterocentrada, etnocentrada y perteneciente a una determinada clase social (heterosexual, blanca y de clase media), llamando la atención sobre las diferencias, que, con frecuencia, se constituyen en fuente de desigualdad, entre las mujeres. Los trabajos de feministas lesbianas como Adrienne $\mathrm{Rich}^{12}$, feministas negras como bell hooks ${ }^{13}$ y Barbara Smith ${ }^{14}$, feministas negras lesbianas como Audre Lorde ${ }^{15}$ y feministas chicanas lesbianas como Gloria Anzaldúa y Cherríe Moraga ${ }^{16}$, entre otras muchas, son magníficos ejemplos de la apuesta por transitar de una noción demasiado unívoca de «mujer» a otra plural de «mujeres».

Es en este marco de discusión en el que Teresa de Lauretis da cuenta del feminismo italiano de la diferencia sexual, prestando especial atención a la obra No creas tener derechos, primero, en su artículo «La esencia del triángulo, o tomarse en serio el riesgo del esencialismo: teoría feminista en Italia, los E.U.A. y Gran Bretaña» y, poco después, en la introducción que elabora para la traducción al inglés de la citada obra. Tanto Lauretis como Zerilli, en El feminismo y el abismo de la libertad, coinciden en apuntar a la configuración del debate en términos de esencialismo/antiesencialismo como una de las razones que explicarían la ausencia de interlocución entre estadounidenses e italianas. En palabras de Zerilli:

A pesar de su subtítulo en italiano («La generación de la libertad femenina en el pensamiento y las vicisitudes de un grupo de mujeres»), las feministas estadounidenses jamás consideraron que Sexual Difference fuese un manifiesto político sobre la libertad de las mujeres. En cambio, fue recibido (en el contexto del debate de la categoría mujeres) como una hipótesis de la irreductible diferencia entre los sexos, de la asimetría simbólica entre lo masculino y lo femenino que condiciona las relaciones de clase, raza, sexualidad y pertenencia nacional. Más allá de las voces de disenso que advirtieron de la apresurada descalificación de los textos feministas (en

11 Cf. Alcoff, L., op. cit., y Scott, J. W., «Deconstructing Equality-Versus-Difference: Or, the Uses of Post-structuralist Theory for Feminism», Feminist Studies, 14, 1, primavera 1988, pp. 33-50.

12 Cf. Rich, A., Sangre, pan y poesía. Prosa escogida 1979-1985, Barcelona, Icaria, 2000; y Sobre mentiras, secretos y silencios, Madrid, horas y HORAS, 2011.

13 Cf. hooks, b., Ain't a Woman: Black Women and Feminism, Boston, South End, 1981.

$14 C f$. Smith, B. (et. all.), All the Women Are Whites, All the Blacks are Men, but Some of Us Are Brave, Nueva York, The Feminist Press, 1982.

15 Cf. Lorde, A., La hermana, la extranjera. Artículos y conferencias, Madrid, horas y HORAS, 2003; y Zami: una biomitografía. Una nueva forma de escribir mi nombre, Madrid, horas y HORAS, 2010.

$16 C f$. Anzaldúa, G. y Moraga, C., (eds.), This Bridge Called My Back: Writtings by Radical Women of Color, Watertown, Persephone, 1981. 
su mayoría europeos) considerados «esencialistas», las feministas estadounidenses siguen pensando que las reivindicaciones de la diferencia sexual, cuando no nos «llevan de vuelta al mito de la mujer», como comenta cáusticamente Monique Wittig, obstruyen toda discusión seria de otras categorías de la diferencia social, sus orígenes políticos y sus efectos ${ }^{17}$.

Lauretis, a diferencia de Zerilli, quien opta, desde el principio, por situar su interpretación de la diferencia sexual en el terreno político, prueba a impugnar el tópico del esencialismo, «tomando en serio», según su expresión, el papel constitutivo de la diferencia sexual en el planteamiento de las italianas. Para esta autora, el pensamiento y la práctica italianas de la diferencia sexual muestran la productividad teórica y política de no temer tomar «los riesgos del esencialismo». Por un lado, partiendo del análisis de los usos del término en el debate estadounidense, Lauretis observa que los significados de éste oscilan «entre una oportuna etiqueta y una palabra-hueca» ${ }^{18}$. De este análisis, destaco la caracterización del esencialismo «como un cargo», esto es, una acusación, al tiempo que como una categoría clasificatoria ${ }^{19}$. Categoría que opera, según desvela nuestra teórica, no sin sarcasmo, movida por un ánimo, fundamentalmente estadounidense, de «tipologizar, definir y marcar los varios «feminismos» a través de una escala ascendente de sofisticación teórico-política donde el «esencialismo» gravita pesadamente en el punto más bajo» ${ }^{20}$. En estas clasificaciones, el feminismo cultural, el separatista, el radical y, en ocasiones, el liberal se asocian con el esencialismo, mientras que el feminismo postestructuralista o deconstructivista aparece en la cúspide de la jerarquización. Es de señalar, como así lo hace Lauretis, que los feminismos de las mujeres de color y del tercer mundo, cuando se recogen, se presentan bajo un tipo propio al que no se aplica el baremo del esencialismo ${ }^{21}$. Finalmente, concluye que el riesgo que planea sobre la posibilidad de un intercambio feminista fructífero no radica tanto en «el riesgo del esencialismo» cuanto en «la sospecha o la clara construcción, por parte de las feministas anglo-americanas, de un esencialismo feminista fantasma» y lo que éste encubre: «el riesgo de cuestionar directamente la institución simbólica y social de la heterosexualidad»22.

Por otro lado, al considerar la diferencia sexual una cuestión de simbolización, a través de la práctica de relaciones de preferencia y de confianza entre mujeres, que las italianas denominan «práctica de affidamento» (a la que dedicaré el próximo apartado), la autora resitúa la discusión al proponer interpretar esta concepción de la diferencia sexual como «un análisis materialista» ${ }^{23}$ y «una formulación política» histórica y socialmente situada ${ }^{24}$.

17 Zerilli, L., op. cit., pp. 190-192.

18 Lauretis, T. de, «La esencia», op. cit., p. 77.

19 Cf.ibíd., p. 81.

20 Ibíd., p. 78.

21 Cf. ibíd., nota 1, pp. 78-79.

22 Ibíd., p. 114. Atender al papel crucial de este planteamiento en la postura de Lauretis excede los límites del presente artículo. He estudiado el estatuto de la heterosexualidad en el feminismo contemporáneo en: Amar la fluidez. Teoría feminista y subjetividad lesbiana, Zaragoza, Eclipsados, 2009.

23 Ibíd., p. 108.

24 Ibíd., p. 113. 
Así pues, las interpretaciones que Lauretis y Zerilli elaboran del pensamiento y la práctica de la Librería de Mujeres de Milán, si bien diversas, comparten el interés de desvincularlo de la acusación de esencialismo y el de ofrecer nuevas claves de lectura. El gesto interpretativo opera, a la vez, como un gesto de desplazamiento: las claves de lectura desarrolladas para abordar la obra de la Librería presentan la virtualidad de modificar los marcos previos de interpretación.

En el giro del feminismo hacia el postestructuralismo cifra Luisa Muraro la «desconexión transatlántica» a la que Rosi Braidotti hace referencia. En un corto e incisivo artículo en el que Muraro considera la tesis de Braidotti, sostiene que la adopción del postestructuralismo por parte del feminismo estadounidense tiene como consecuencia la pérdida de «la fecundidad de la interacción entre práctica y teoría» ${ }^{25}$, puesto que se acepta «un saber elaborado independientemente de la lucha política de las mujeres, en el cual «mujer» es una noción deducida ${ }^{26}$. Los indicios de esta pérdida serían los siguientes:

La confirmación de lo que se ha perdido, la hemos tenido con el apagarse de palabras como diferencia sexual y asimetría que han sido vueltas hacia atrás, la primera reducida a designar una construcción patriarcal (o una tacha de esencialismo o naturalismo para aquellas que la usan), la segunda privada de cualquier capacidad de relanzamiento hacia un sentido libre de la diferencia, reducida a un estático sinónimo de desigualdad ${ }^{27}$.

Aunque ni Lauretis ni Zerilli citan a Muraro, y probablemente discutirían la valoración de los fenómenos analizados, resulta significativo que ambas interpretaciones incidan sobre las dos cuestiones señaladas por Muraro como claves hermenéuticas para evaluar la desconexión transatlántica, esto es, la comprensión de la diferencia sexual y la conceptualización de las nociones de asimetría y diferencia.

\section{Affidamento y libertad femenina, o la audacia de la Librería de Mujeres de Milán²8}

En 1987 las mujeres de la Librería de Milán publican No creas tener derechos, título que no dejó, ni aún deja, indiferente. La expresión la tomaron de la filósofa Simone Weil, con cuya cita se abre el texto. Provocador título seguido de un prometedor subtítulo: $L a$ generación de la libertad femenina en las ideas y vivencias de un grupo de mujeres. Ésta es una obra de escritura colectiva que narra las experiencias políticas de diversos grupos de mujeres de Milán, principalmente, entre 1966 y 1986.

25 Muraro, L., «A partire da sé, il magico affacciarsi del nuovo», Il Manifesto, 5 de mayo de 2006, en http://www. ildialogo.org/filosofia/apartiredase11052006.htm, p. 3. Consultado el 20 de marzo de 2012. Traducciones mías.

26 Ibíd., p. 3.

27 Muraro, L., op. cit., pp. 3-4. No obstante, otras pensadoras italianas de la diferencia sexual han esbozado vínculos entre éste y el feminismo postestructuralista: $c f$. Dominijanni, I., «El estrabismo de Venus: una mirada a la crisis de la política desde la política de la diferencia», Duoda (Barcelona), nº 40, 2011, pp. 13-34.

28 El calificativo me lo ha sugerido la lectura de Zerilli quien se refiere al «audaz postulado de la libertad femenina» (ibíd., p. 198). 
Ni a Lauretis ni a Zerilli se les escapa la novedad de la idea de libertad femenina, término que chispea desde la portada y del cual la obra constituye el relato de su descubrimiento. Relato, como subraya Lauretis, presentado por las propias artífices como una narración parcial y contingente, siendo éstas las características que la conducen a considerarlo una muestra de conocimiento «localizado» ${ }^{29}$. Para esta autora, la noción de libertad femenina supone una auténtica «ruptura epistemológica» con respecto al pensamiento occidental ${ }^{30}$; para Zerilli, sin embargo, que busca desplazar el papel de la epistemología en el feminismo, implica una radical reformulación de la política.

Zerilli hace girar su interpretación de la libertad femenina en torno a la comprensión arendtiana de la libertad política, a saber, una noción de libertad descrita como inaugural, es decir, la cualidad de dar inicio a algo nuevo, y constructora de mundo, esto es, la cualidad de crear sus propias condiciones de posibilidad a través de su práctica. En cambio, Lauretis apunta a la noción de affidamento como clave hermenéutica, puesto que estima que de ella dependen la mencionada noción y la tesis del carácter originario de la diferencia sexual. A este respecto, sostiene que en «el concepto de affidamento a través de la disparidad» es donde radica «la originalidad de esta teoría de la diferencia sexual tanto como su principal dificultad» ${ }^{31}$.

¿En qué consiste esta libertad adjetivada de femenina? Veamos de qué se trata la «práctica de affidamento» y qué relación guarda con la libertad.

Tras más de diez años de práctica política y teórica, las mujeres de la Librería de Milán se encontraron ante la dificultad de «traducir» los resultados creativos de las prácticas políticas desarrolladas por el movimiento de mujeres a las relaciones sociales. Este obstáculo lo abordaron en «Más mujeres que hombres» ${ }^{32}$, un texto también de escritura colectiva, publicado en 1983, cuatro años antes que No creas tener derechos y retomado en la citada obra. En él, las autoras argumentaron que las mediaciones sociales y simbólicas existentes respondían a una construcción masculina falogocéntrica del mundo, pese a su autoproclamada neutralidad, y expusieron que la posibilidad de inscribir social y simbólicamente la diferencia sexual requería la elaboración de mediaciones femeninas, unas mediaciones tales que mostraran la parcialidad masculina y construyeran positivamente la femenina. La práctica política de las feministas italianas de la diferencia sexual se articuló, entonces, en torno a la propuesta de constituir un «mundo común de las mujeres» ${ }^{33}$, en la evocadora formulación de Adrienne Rich. En palabras de las mujeres de la Librería de Milán, se trata de urdir

(...) una trama de relaciones preferentes entre mujeres, en las que la experiencia asociada al ser mujer se refuerza en el reconocimiento recíproco y se inventan las maneras de traducirla en realidad social. A esto le llamamos mundo común de las

29 Lauretis, T. de, «La esencia», op. cit., p. 107.

30 Ibíd., p. 108.

31 Ibíd., p. 104. He modificado ligeramente la traducción al castellano.

32 Librería de Mujeres de Milán, «Más mujeres que hombres. Sottosopra verde (enero, 1983)», en: Librería de Mujeres de Milán: La cultura patas arriba. Selección de la Revista Sottosopra 1973-1996, Madrid, horas y HORAS, 2006, pp. 107-129.

33 Ibíd., p. 119. Cf. Rich, A., «Condiciones de trabajo: el mundo común de las mujeres (1976)», en: Rich, A.: Sobre mentiras, secretos y silencios, Madrid, horas y HORAS, 2011, pp. 295-312. 
mujeres, una trama de relaciones y de referencias a nuestras semejantes capaz de registrar, de dar consistencia y eficacia a nuestra experiencia en su integridad, recuperando y desarrollando también lo que ya han sabido hacer, en condiciones difíciles, como destellos de luz, muchas mujeres ${ }^{34}$.

Ahora bien, esta urdimbre de «relaciones preferentes entre mujeres» no implica asumir alguna suerte de identidad homogénea, ya dada o susceptible de ser definida, sino, más bien, demanda la puesta en juego de la disparidad entre mujeres, sacando «a la luz deseos y necesidades subjetivas enraizadas en historias individuales diversas ${ }^{35}$, contando con «las múltiples experiencias, posibilidades y diversidad» ${ }^{36}$ que se dan entre las mujeres. Es lo que las mujeres de la Librería de Milán han llamado la «práctica de la disparidad», que late en el corazón de la «práctica de las relaciones entre mujeres» o affidamento, relación en la que una mujer confía en otra u otras a la hora de establecer sus vínculos con el mundo. Una vez desvelado «que el pacto social fue concebido teniendo presente la experiencia masculina» ${ }^{37}$, las feministas de la Librería de Milán invitan a las mujeres a «romper por la mitad el pacto social y medirse con el mundo sobre la base de su diferencia» ${ }^{38}$, a contratar entre ellas un nuevo pacto a través de la práctica de affidamento.

Las mujeres de la Librería de Milán consideran que la singularidad de cada mujer, así como la constitución de una comunidad, depende de la articulación de mediaciones femeninas. $\mathrm{O}$, dicho de otro modo, que la singularidad de las mujeres procede de «la atribución de autoridad y valor a otra mujer en las relaciones con el mundo» ${ }^{39}$, lo que posibilita una «estructura simbólica de mediación» ${ }^{40}$. En otras palabras, «el simple reconocimiento en la relación entre mujeres es el acto sobre el cual se fundamenta en la práctica la libertad femenina ${ }^{41}$. En suma:

La libertad femenina [...] no se obtiene con la admisión en la sociedad masculina ni como resultado de una reivindicación frente a ella, sino a través del contrato elemental en virtud del cual una mujer intercambia con otras semejantes a ella el reconocimiento de la propia existencia contra la aceptación significada de la común pertenencia al sexo femenino ${ }^{42}$.

Así pues, la significación libre de la propia existencia en la relación de affidamento permite diluir «la aceptación significada de la común pertenencia al sexo femenino», es decir, los significados dados a la diferencia sexual, y hace emerger la diferencia sexual como significante y como «fuente inagotable de significados siempre nuevos» ${ }^{43}$. Así

34 Librería de Mujeres de Milán, «Más mujeres», op. cit., p. 121.

35 Librería de Mujeres de Milán, No creas, op. cit., p. 90.

36 Ibíd., p. 120.

37 Ibíd., pp. 209-210.

38 Ibíd., p. 223.

39 Ibíd., p. 168.

40 Ibíd., p. 163.

41 Ibíd., p. 199.

42 Ibíd., p. 216.

43 Ibíd., p. 192. 
entendida, la diferencia sexual no depende de contenidos específicos, sean éstos valores éticos o cualquiera otros, no especifica contenido alguno, sino que hace significante la diferencia sexual, que queda abierta al libre juego de la significación. Es en este sentido en el que podríamos considerar la interpretación materialista de Teresa de Lauretis, a la que me referí en el primer apartado, según la cual la comprensión de la diferencia sexual ofrecida por la Librería de Mujeres de Milán concierne a una cuestión de simbolización. Esta concepción de diferencia sexual, pensada como diferencia humana original, referiría a «una diferencia de simbolización», es decir, «a una diferente producción de referencia y sentido de un cuerpo particular de conocimiento ${ }^{44}$. En esta línea, Zerilli sostiene que es la práctica de autorización, a través de la «figuración simbólica» (la madre simbólica), lo que permite a la Librería de Mujeres de Milán presentar la libertad en términos realizables, esto es, como una práctica de la vida cotidiana, pues «[a] falta de esta figuración [simbólica], la experiencia de la libertad estará siempre fuera de nuestro alcance y no servirá como recurso para futuras innovaciones ${ }^{45}$.

Lo anterior explica por qué el «simple reconocimiento» entrañaba, sin embargo, un importante trabajo político «sobre lo simbólico» ${ }^{46}$ : era preciso dar «nombre y forma social a lo que, sin nombre y sin forma, sucedía entre mujeres» ${ }^{47}$, dotar al orden dado de un sentido distinto. La libertad femenina tiene lugar «en la nueva combinación de relaciones libres entre mujeres, a través de palabras y de gestos de la vida cotidiana ${ }^{48}$. En esta práctica política son las mismas mujeres las que garantizan la libertad femenina, pues, afirman las autoras, «la libertad es el único medio para alcanzar la libertad» ${ }^{49}$.

La libertad no es pensada, por tanto, como una meta remota, ni tampoco se reduce a la libertad negativa ni a los derechos individuales garantizados por la ley; sino que es concebida como una potencia que genera libertad y mundo al mismo tiempo. La libertad es entendida, entonces, como aquello que se crea en la práctica cotidiana a través de su ejercicio, en el reconocimiento y agradecimiento de una mujer hacia las otras mujeres como fundantes de su vinculación con el mundo. La libertad no se tiene como se tiene una posesión, no se tiene, en definitiva; sino que surge en y de la relación. Como ha dicho Diana Sartori, se trata de «una libertad con»: «una libertad que existe en relación. O, mejor, es una práctica de libertad entendida como práctica de relación $»^{50}$. Es, pues, una libertad relacional.

\section{3. ¿Cómo pensar las diferencias entre las mujeres? Debate a dos orillas}

Linda Zerilli propone considerar la diferencia sexual como una práctica política en lugar de como un postulado trascendental o una cuestión de verdad. En este sentido, se

44 Lauretis, T. de, «La esencia», op. cit., p. 108.

45 Zerilli, L., op. cit., p. 204.

46 Librería de Mujeres de Milán, No creas, op.cit., p. 157. Cf. Muraro, L., El orden simbólico de la madre, Madrid, horas y HORAS, 1994.

47 Ibíd., p. 227.

48 Ibíd.., p. 183.

49 Ibíd., p. 228. Cf. también, ibíd., p. 221.

50 Sartori, D., «Libertad «con». La orientación de las relaciones», Duoda (Barcelona), n 26, 2004, p. 105. Para la idea de la libertad como creación: $c f$. Muraro, L., «Feminismo y política de las mujeres», Duoda (Barcelona), $\mathrm{n}^{\circ} 28,2005$, pp. 39-47. 
halla en sintonía con la interpretación que ofrecen las propias feministas italianas. No obstante, su originalidad radica, a mi juicio, en situar la lectura de la obra de la Librería en el marco de la filosofía política arendtiana, lo que la lleva a entender la diferencia sexual como una práctica de libertad política, y en introducir esta perspectiva en el contexto del feminismo estadounidense. Contexto en el que, siguiendo su análisis, los marcos de interpretación, centrados o bien en la cuestión social o bien en la cuestión del sujeto, habrían impedido la comprensión de la libertad como acción o como «cuestión del mundo» ${ }^{51}$. Según Zerilli, el trabajo de la Librería constituye un ejemplo de este modo de concebir la libertad y de una práctica política que se hace cargo de su propia contingencia; ya que la autora encuentra en la libertad femenina de las italianas una noción «radicalmente infundada: ni fundacional ni consecuencialista», debido a que «su única raison d'être es ella misma» ${ }^{52}$.

Las mujeres de la Librería de Milán no reducen la cuestión de la libertad a la liberación de la opresión ni a la obtención de derechos ${ }^{53}$, sino que su preocupación central es la libertad entendida como capacidad de fundar nuevas formas de asociación política, que no pueden pensarse independientemente de la diferencia sexual. Donde ésta no ha de ser destruida ni trascendida, sino resimbolizada, transformándola «de causa social de no-libertad en principio de nuestra libertad» ${ }^{54}$. Al obrar tal transformación, las italianas, sostiene Zerilli, ponen en juego «los rasgos creativos y disruptivos de la libertad política y la práctica cotidiana de la construcción-de-mundo ${ }^{55}$. Esta práctica infundada y contingente de libertad ilustra, precisamente, el tipo de concepción de la política con la que Zerilli propone repensar el feminismo en ausencia de una categoría unificada de mujeres.

Las mujeres de la Librería de Milán estiman que la libertad femenina exige la simbolización de la diferencia sexual y que es en el marco de esta simbolización en el que tanto las diferencias entre mujeres como la singularidad de cada una de ellas pueden ser pensadas y activadas políticamente. No obstante, como adelantamos, en el contexto estadounidense se tendió a desarrollar otro planteamiento: aquel según el cual la noción de diferencia sexual contribuye a ocultar las diferencias entre las mujeres. En la medida en que la diferencia sexual era pensada exclusivamente en términos de diferencia (jerarquizada) entre hombre y mujer, las diferencias entre las mujeres o bien eran minimizadas o bien no encontraban articulación política.

Tal vez, como sugiere Zerilli, las diferencias entre mujeres eran minimizadas porque las feministas no acertaban a hallar la manera de convertirlas en políticamente significativas sin socavar un cierto ideal de comunidad basado en la identificación recíproca. A este respecto, la autora sostiene que las feministas italianas de la diferencia sexual nos permiten reflexionar sobre dos cuestiones que parecen haber pasado inadvertidas en el debate estadounidense: el papel político de la capacidad de juicio y la comprensión de la diferencia como disparidad. En primer lugar, Zerilli relaciona la problemática acerca del reconocimiento de las diferen-

51 Zerilli, L., op. cit., p. 53.

52 Ibíd., p. 197.

53 Acerca de la relación entre el pensamiento italiano de la diferencia sexual y los derechos: $c f$. Hernández Piñero, A., «Igualdad, diferencia: genealogías feministas», Feminismo/s (Alicante), n 15, 2010, pp. 75-94.

54 Librería de Mujeres de Milán, No creas, op. cit., p. 185.

55 Zerilli, L., op. cit., p. 198. 
cias entre mujeres con el desarrollo de la capacidad del juicio como práctica política: «[a] falta de un juicio, a falta de una manera de evaluar y articular las diferencias, éstas quedan reducidas prácticamente a nada». Aún «[d]ebidamente notadas, incluso celebradas, pero no juzgadas, las diferencias son tan poco significativas» como cuando son abiertamente negadas o ignoradas ${ }^{56}$.

Ahora bien, ¿cómo juzgarlas? ¿En qué consiste esta práctica que Zerilli vincula con la capacidad de juicio y califica de política? En la propuesta de las mujeres de la Librería de Milán, el juicio procede de las propias mujeres, se articula entre mujeres. Por lo tanto, los criterios para «evaluar y articular las diferencias» provienen de la relación entre las mujeres, donde cada otra se convierte en (potencial) interlocutora dispar; en ningún caso remiten a una instancia externa. El juicio, entonces, es ejercitado en el contexto del reconocimiento de la disparidad.

Las diferencias entre mujeres entendidas como disparidad representa la segunda cuestión sobre la que Zerilli llama nuestra atención. La autora señala las importantes divergencias entre la manera de plantear este debate por parte de las feministas italianas y de las estadounidenses, cuyo eje gira en torno a la conceptualización de la noción de diferencias. En el abordaje que efectúan las feministas italianas de la diferencia sexual de las diferencias entre mujeres, la disparidad no se reduce al registro de la desigualdad que, por otra parte, las autoras no niegan. En cambio, en el ámbito feminista estadounidense este debate se ha planteado fundamentalmente en términos de desigualdad.

Para las mujeres de la Librería de Milán, la disparidad indica una dimensión de asimetría constitutiva de la diversidad humana, de irreductibilidad. Implica, además, otro elemento que no nos permite considerar los términos disparidad y diversidad como sinónimos, éste último de uso frecuente en el contexto feminista estadounidense (y anglosajón, en general) a partir del debate acerca de las diferencias entre mujeres ${ }^{57}$. A saber, la idea de preferencia: la disparidad requiere elección además de asimetría. En este sentido, las autoras observan que, al principio, la elección les pareció banal; sin embargo, en ella estaba contenida una apuesta original y radical: atribuir valor entre mujeres o, dicho de otro modo, otorgar al valor una fuente femenina. La práctica de la disparidad conlleva, entonces, siguiendo a Zerilli, una práctica de juicio político en tanto supone atribuir valor.

La disparidad refiere a diferencias no eliminables, «diferencias cualitativas», cuya cualidad consiste en conservar «el valor original de una experiencia humana $»^{58}$, es decir, la cualidad de aquello que no es contrastable según una medida pretendidamente neutra y universal ${ }^{59}$. Las autoras reconocen la dificultad de discernir entre las disparidades vinculadas a la desigualdad y aquéllas que no lo están, pues «las disparidades se presentan confusamente enmarañadas» ${ }^{60}$. No obstante, consideran posible pensar en diferencias «ineliminables y en algunos casos provechosas» ${ }^{61}$. En este sentido argumentan que la

56 Ibíd., p. 212.

57 Cf. Alice, L., «Diversity», en: L. Code (ed.): Encyclopedia of Feminist Theories, Londres, Routledge, 2000, p. 142.

58 Librería de Mujeres de Milán, No creas, op. cit., p. 204.

59 Cf., p.e., ibid., pp. 203-205.

60 Ibíd., p. 203.

61 Ibíd. 
tendencia a concebir la disparidad como desigualdad y, en consecuencia, en términos de (in)justicia representa uno de los aspectos más poderosos y persistentes que contribuyen a tal dificultad, habida cuenta del carácter homologador de la justicia:

Si el valor originario de la diferencia no está a salvo, si no hay diferencias cualitativas, si todo se confronta con todo y en cada disparidad quiere verse un conflicto de poder-derecho, entonces finalmente las únicas diferencias, las únicas medidas, las que se imponen definitivamente, son las de la objetividad del poder ${ }^{62}$.

La disparidad guarda una relación de anterioridad con respecto a la justicia y, en todo caso, ésta tendría que orientarse en función de aquélla, o sea, tanto la reflexión sobre como la demanda de justicia habría de estar mediada por la diferencia sexual.

En cambio, en el feminismo estadounidense, a raíz de las críticas y los análisis llevados a cabo, fundamentalmente, por las feministas negras y de color y las feministas lesbianas, la cuestión de las diferencias entre mujeres se ha elaborado en torno a la pertenencia de las mujeres a distintos grupos sociales, tales como la clase, la raza y la sexualidad, pertenencias que complejizan cualquier posible comprensión unívoca del «ser mujer». Autoras tan diversas entre sí como Audre Lorde, Adrienne Rich, Barbara Smith, Gloria Anzaldúa, Teresa de Lauretis, Nancy Fraser o Iris Young, por citar sólo algunas, han considerado necesario para el feminismo dar cuenta de estas pertenencias múltiples así como del modo en que estas pertenencias operan, también, aunque no exclusivamente, como fuentes de desigualdad. Esta idea fue tempranamente formulada en 1977 por La Colectiva del Río Combahee en términos de simultaneidad de las opresiones ${ }^{63}$. Ahora bien, cabe constatar, desde mi punto de vista, una importante divergencia entre este planteamiento de finales de la década de los setenta y las propuestas de la década de los noventa: mientras que La Colectiva vincula la idea de la simultaneidad de los ejes de diferenciación-desigualdad con la política de la identidad; la tendencia en la década de los noventa se cifra, por el contrario, en la relación entre la simultaneidad y la crítica a la política de la identidad, convertida desde mediados de la década de los ochenta en objeto de fuerte controversia debido a las críticas de esencialismo dirigidas contra ella.

Así, como observa $\mathrm{M}^{\mathrm{a}}$ José Guerra, los cambios acontecidos en la definición del género en la teoría feminista estadounidense se juegan, en los noventa, en la desconexión de esta noción con respecto a la de identidad, pues se buscaba abordar la problemática de «cómo conceptualizar a las mujeres como grupo social sin forzar «normalización» alguna» ${ }^{64}$. En sentido análogo se pronuncia Rosi Braidotti cuando sostiene que las teóricas de género de la década de los noventa comparten la concepción de la subjetividad como posición. Desde esta perspectiva, el género se caracteriza como posición social dada y la subjetividad se constituye en y a partir de la intersección e interacción de distintos ejes de diferenciación

62 Ibíd., p. 205.

$63 C f$. Colectiva del Río Combahee, «Una declaración feminista negra», en: A. del Castillo y C. Moraga (eds.): Esta Puente, mi espalda. Voces de mujeres tercermundistas en Estados Unidos, San Francisco, ism press, 1999, pp. 175-176.

64 Guerra Palmero, M. J., «Género: debates feministas en torno a una categoría», Arenal (Granada), vol. 7, n 1, enero-junio 2000, p. 224. Cf. ibíd., pp. 220-239. 
tales como el género, la clase, la raza, la etnia, la sexualidad, la edad ${ }^{65}$, sin predeterminar la manera en que cada una se identifique o autorrepresente.

Sin embargo, Zerilli no parece tomar en cuenta la importante divergencia que acabo de exponer, debido a que tiende a emplear las categorías generales de segunda y tercera ola. No deja de sorprender este recurso a un nivel de generalización tal que impide atender a los desplazamientos y transformaciones acaecidas en el feminismo estadounidense con respecto al debate que nos ocupa en una argumentación tan cuidada como la de Zerilli.

Nuestra autora considera que cualquier planteamiento que presente a las mujeres «como grupo sociológico o sujeto social» incurre en la búsqueda moderna de un fundamento nopolítico o pre-político para la política, ya que haría depender la formulación política de una pertenencia previa, y, por consiguiente, enlaza con una comprensión fundacionista y utilitarista de la política, contraria a la que ella propone inspirada en Hannah Arendt. Lo cual entronca, a mi juicio, con la crítica que Zerilli efectúa a la conceptualización de la noción de diferencias por parte del feminismo estadounidense. La autora desarrolla este análisis en contraposición con el concepto arendtiano de pluralidad. Según ella, la pluralidad en el debate acerca de las diferencias entre las mujeres es entendida en términos de «diferencias sociales», es decir, como diferencias empíricas (el «hecho raso de las diferencias» - escribe $\left.{ }^{66}\right)$ o como «un mero concepto existencial» ${ }^{67}$. Zerilli objeta que esta manera de entender la pluralidad inviste políticamente a unas diferencias cuyo carácter es social, o sea, que refieren a lo empírico o a lo dado («que están allí desde un comienzo» - apunta). Para la teórica, es preciso crear una relación para que las diferencias se conviertan en políticas: «la pluralidad no es un hecho demográfico o existencial sino una relación política con las diferencias sociales; requiere que yo haga algo en relación con esas diferencias, que las tome en cuenta de alguna manera políticamente significativa ${ }^{68}$. Por el contrario, Zerilli encuentra en la Librería de Mujeres de Milán un ejemplo de práctica política que permite pensar a las mujeres «como colectividad política», lo que para la autora significa «un frágil logro de las prácticas de libertad», que reconoce que la formación del ««nosotras» del feminismo» es «irreductiblemente contingente ${ }^{69}$, siendo la contingencia «la forma de ser de la libertad política ${ }^{70}$, en palabras de Fina Birulés.

Ahora bien, por un lado, me parece que esta caracterización adeuda demasiado a la distinción arendtiana entre lo social y lo político, entre lo dado y la acción y, en consecuencia, pese a las precauciones tomadas por Zerilli, ésta sería susceptible a las críticas feministas que han rechazado tales distinciones, de las que encontramos una síntesis en el recorrido que $\mathrm{M}^{\mathrm{a}}$ José Guerra traza acerca de las lecturas feministas de Arendt y a las que ella misma se suma ${ }^{71}$. Por otro lado, la descripción de la pluralidad como relación política podría aplicarse a las teorías de la posicionalidad a las que he aludido.

$65 C f$. Braidotti, R., Sujetos nómades. Corporización y diferencia sexual en la teoría feminista contemporánea, Buenos Aires, Paidós, 2000, pp. 26-30.

66 Zerilli, L., op. cit., p. 230.

67 Ibíd., p. 277.

68 Ibíd., p. 212

69 Ibíd., pp. 65-66. Zerilli está citando La condición humana de Hannah Arendt (Barcelona, Paidós, 2005).

70 Birulés, F., «Mundo común, feminismo y mitología», Isegoría (Madrid), nº 49, julio-diciembre 2013, p. 413.

71 Guerra Palmero, M. J., «Arendt y los feminismos contemporáneos: ontología y política», Daímon (Murcia), Suplemento 4, 2011, pp, 203-212. 
En contraste, Lauretis advierte que la manera de abordar las diferencias entre mujeres por parte de la Librería de Milán a través de las prácticas del affidamento y la disparidad dejan «muy poco espacio para las diferencias y las divisiones entre $-\mathrm{y}$ dentro- de las mujeres» ${ }^{72}$. Pese a ello, Lauretis no considera que la dificultad resida en el recurso a la diferencia sexual, es decir, que ésta impida abordar las diferencias entre mujeres, sino que, más bien, se inclina a pensar que éstas han de abordarse en relación con aquélla.

\section{Tender puentes}

He sostenido que las recepciones del feminismo italiano de la diferencia sexual, excepcionales en el ámbito estadounidense, elaboradas por Teresa de Lauretis y Linda Zerilli permiten a estas autoras intervenir de manera creativa en sus propios contextos de discusión. A fin de argumentarlo, por un lado, he tratado de mostrar cómo la lectura de No creas tener derechos conduce a ambas autoras a cuestionar los términos en los que se estaban articulando, en el caso de Lauretis, o se habían articulado, en el de Zerilli, los debates acerca del postestructuralismo y de las diferencias entre las mujeres, a saber, en términos de esencialismo versus antiesencialismo y diferencia sexual versus diferencias. A su vez, he intentado explicar que la configuración de las discusiones en tales términos constituía la razón de la casi inexistente interlocución entre el feminismo estadounidense y el feminismo italiano de la diferencia sexual.

Por otro lado, he procurado dar cuenta de las claves interpretativas novedosas que cada una de las autoras ha desarrollado: ambas desplazan la interpretación desde las críticas de esencialismo hacia una lectura materialista de producción diferencial de referencia y significado, en el caso de Lauretis, u otra orientada por una comprensión de la libertad política de filiación arendtiana, en la propuesta de Zerilli. Las dos, igualmente, destacan la originalidad y radicalidad de la noción de libertad femenina acuñada por las mujeres de la Librería de Milán.

Si bien, para Lauretis, la noción de libertad femenina supone una auténtica «ruptura epistemológica» con respecto al pensamiento occidental y ofrece un nuevo tipo de conocimiento, un conocimiento situado; para Zerilli, que busca desarrollar una concepción no epistemológica de la política, implica una radical reformulación de ésta. Nuestra última autora encuentra en la libertad femenina, y en la práctica de affidamento que la genera, una práctica infundada y contingente que ejemplifica el tipo de concepción de la política a partir de la que propone repensar el feminismo sin el concurso de una categoría unificada de mujeres. No obstante su actitud anticognitivista, como la denomina $\mathrm{M}^{\mathrm{a}}$ José Guerra $^{73}$, o, quizás, precisamente debido a ella, el trabajo de la Librería de Mujeres de Milán ilustra una concepción de la teoría que rehúye «el anhelo de generalidad» ${ }^{74}$ y que brinda una relación tal entre teoría y práctica que posibilita pensar lo particular en ausencia de reglas universales. La noción arendtiana de juicio recogería ambos aspectos y Zerilli argumenta en la dirección de vincular la práctica de la disparidad con la capacidad de elaborar juicios. A este respecto, he abordado y problematizado el análisis que lleva a cabo la autora sobre el tratamiento de las diferencias entre mujeres que hacen tanto las feministas estadounidenses como las feministas italianas de la diferencia sexual.

72 Lauretis, T. de, «La esencia», op. cit., p. 113.

73 Guerra Palmero, M. J., «Arendt», op. cit., p. 210.

74 Zerilli, L., op. cit., p. 80. 
He tomado en consideración la hipótesis de Zerilli según la cual las diferencias entre mujeres habían sido minimizadas porque las feministas no acertaban a hallar la manera de convertirlas en políticamente significativas y que tal cosa requiere «una manera de evaluar y articular las diferencias», razón por la que estima que la propuesta de las mujeres de la Librería de Milán permite llamar la atención sobre el papel político de la capacidad de juicio. Cuestión que, junto con la caracterización de la diferencia como disparidad, había pasado inadvertida en el debate estadounidense. Finalmente, aún compartiendo con Zerilli las apreciaciones anteriores, he apuntado las críticas expuestas por Lauretis acerca de la dificultad de articular las diferencias entre mujeres, de sexualidad, clase, raza, entre otras, en el marco de la disparidad. Creo que éste sigue siendo un tema abierto de conflicto y, por tanto, de reflexión.

En suma, los trabajos de Teresa de Lauretis y Linda Zerilli resultan sumamente sugerentes e inspiradores: por una parte, por su originalidad y por su audacia a la hora de ofrecer lecturas que conmueven los marcos interpretativos previos y abren nuevas posibilidades hermenéuticas; y, por otra, debido a lo que atribuiría a una actitud intelectual y política, una actitud que tiende puentes entre diferentes corrientes del pensamiento y de la práctica feministas sin evitar, en ningún caso, los conflictos, sino buscando el modo de hacerlos tratables. Una actitud que tiende puentes sobre el abismo. 
